\title{
ARTICLE
}

\section{Electronic structure of $\mathrm{URu}_{2} \mathrm{Si}_{2}$ studied by photoelectron spectroscopy (INVITED)}

\author{
Shin-ichi Fujimori ${ }^{\mathrm{a}^{*}}$, Yukiharu Takeda ${ }^{\mathrm{a}}$, Tetsuo Okane ${ }^{\mathrm{a}}$, Yuji Saitoh ${ }^{\mathrm{a}}$, Atsushi Fujimori ${ }^{\mathrm{a}, \mathrm{b}}$, Hiroshi Yamagami ${ }^{\mathrm{a}, \mathrm{c}}$, \\ Yoshinori Haga $^{\mathrm{d}}$, Etsuji Yamamoto ${ }^{\mathrm{d}}$ and Yoshichika Ōnuki ${ }^{\mathrm{e}}$ \\ ${ }^{a}$ Condensed Matter Science Division, Japan Atomic Energy Agency, Sayo, Hyogo, 679-5148, Japan; ${ }^{b}$ Department of Physics, \\ University of Tokyo, Hongo, Tokyo, 113-0033, Japan; ' Department of Physics, Faculty of Science, Kyoto \\ Sangyo University, Kyoto, 603-8555, Japan; 'Advanced Science Research Center, Japan Atomic Energy Agency, Tokai, Ibaraki, \\ 319-1195, Japan; ${ }^{e}$ Faculty of Science, University of the Ryukyus, Nishihara, Okinawa, 903-0213, Japan
}

\begin{abstract}
The electronic structure of $\mathrm{URu}_{2} \mathrm{Si}_{2}$ in the paramagnetic phase was studied by photoelectron spectroscopy. The comparison of the valence-band and core-level spectra of $\mathrm{URu}_{2} \mathrm{Si}_{2}$ with those of itinerant $\mathrm{U} 5 f$ compound $\mathrm{UB}_{2}$ and localized $\mathrm{U} 5 f$ compound $\mathrm{UPd}_{3}$ suggests that the $\mathrm{U} 5 f$ electrons in $\mathrm{URu}_{2} \mathrm{Si}_{2}$ have essentially itinerant character, but there also exists an electron correlation e ect. Comparison of angle-resolved photoelectron spectroscopy (ARPES) spectra of $\mathrm{URu}_{2} \mathrm{Si}_{2}$ and $\mathrm{ThRu}_{2} \mathrm{Si}_{2}$ revealed that $\mathrm{U} 5 f$ electrons forms dispersive bands in the vicinity of $E_{\mathrm{F}}$, suggesting that the $\mathrm{U} 5 f$ states have itinerant character in $\mathrm{URu}_{2} \mathrm{Si}_{2}$. This is in contrast to the relationship between the ARPES spectra of $\mathrm{CeRu}_{2} \mathrm{Si}_{2}$ and $\mathrm{LaRu}_{2} \mathrm{Si}_{2}$ where Ce $4 f$ electrons are nearly localized in $\mathrm{CeRu}_{2} \mathrm{Si}_{2}$.
\end{abstract}

Keywords: $\mathrm{URu}_{2} \mathrm{Si}_{2}$; photoelectron spectroscopy

\section{Introduction}

Uranium compounds exhibit a rich variety of physical properties. In particular, the coexistence of superconductivity and magnetic ordering is one of the most significant properties among these compounds [1]. Among them, $\mathrm{URu}_{2} \mathrm{Si}_{2}$ attracts much attention due to its enigmatic hidden order transition at $T_{\mathrm{HO}}=17.5 \mathrm{~K}$ [2]. Although there are a number of theoretical and experimental studies on this compound, its order parameter has not been identified for more than thirty years $[3,4]$. Meanwhile, photoelectron spectroscopy is a very powerful experimental technique to reveal the electronic structure of materials. In particular, angle resolved photoelectron spectroscopy (ARPES) has been used to reveal the band structure and Fermi surface of strongly correlated materials. Numbers of photoelectron spectroscopy studies have been also performed for $\mathrm{URu}_{2} \mathrm{Si}_{2}$ to clarify its electronic structure. On the other hand, the nature of $\mathrm{U} 5 f$ states in $\mathrm{URu}_{2} \mathrm{Si}_{2}$ even in the paramagnetic phase has been still controversial issue $[5,6]$.

In the present paper, the electronic structure of $\mathrm{URu}_{2} \mathrm{Si}_{2}$ in the paramagnetic phase is studied by angle integrated photoelectron spectroscopy (AIPES) valence-band and core-level studies. The results are compared with the AIPES spectra of typical itinerant $\mathrm{UB}_{2}$ and localized compounds $\mathrm{UPd}_{3}$. Furthermore, angle resolved photoelectron spectroscopy (ARPES) was also applied for $\mathrm{URu}_{2} \mathrm{Si}_{2}$ and its non- $f$ analogue $\mathrm{ThRu}_{2} \mathrm{Si}_{2}$ $[7,8]$. The results are compared with the ARPES spectra of their $4 f$ analogs $\mathrm{CeRu}_{2} \mathrm{Si}_{2}$ and $\mathrm{LaRu}_{2} \mathrm{Si}_{2}$ [9].

\section{Experimental procedures}

Photoemission experiments were performed at the soft X-ray beamline BL23SU of SPring-8 $[10,11]$. The overall energy resolution in angle-integrated photoemission (AIPES) experiments at $h v=800$ $\mathrm{eV}$ was about $140 \mathrm{meV}$, and that in ARPES experiments at $h v=735-760 \mathrm{eV}$ was $100-140$ $\mathrm{meV}$, depending on the photon energies. Clean sample surfaces were obtained by cleaving the single crystal samples in situ with the surface perpendicular to the $c$ axis under ultra-high vacuum (UHV) condition. The vacuum during the course of measurements was typically $<3 \times 10^{-8} \mathrm{~Pa}$, and the sample surfaces were stable for the duration of measurements (1-2 days) since no signficant changes had been observed in ARPES spectra during the periods. The positions of ARPES cuts were determined by assuming a free-electron final state with an inner potential of $V_{0}=12 \mathrm{eV}$ by taking into account the momentum of incident photon [12].

*Corresponding author. Email: fujimori@spring8.or.jp 

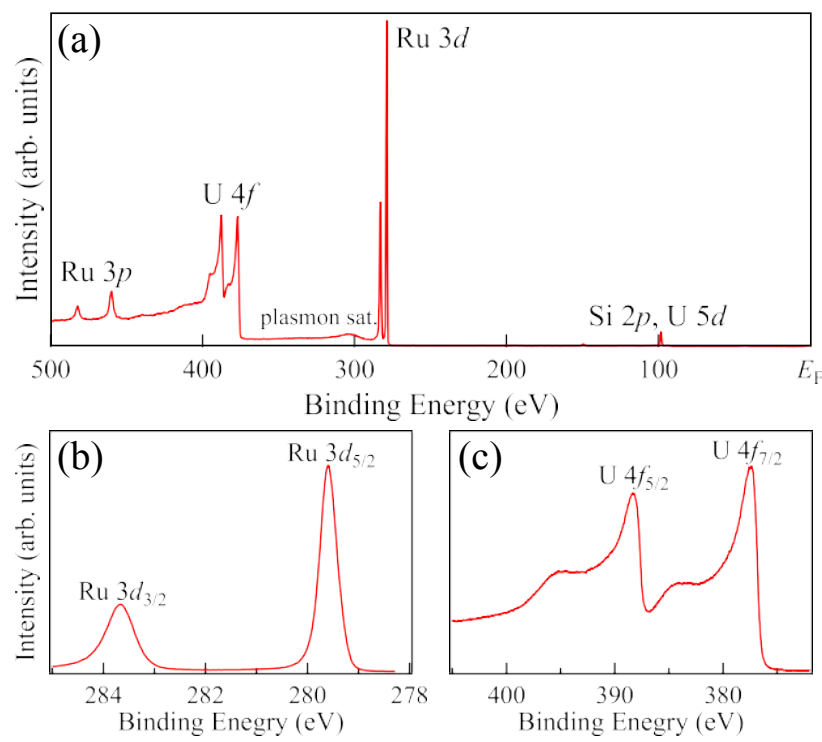

Figure 1. Angle-integrated photoemission spectra of $\mathrm{URu}_{2} \mathrm{Si}_{2}$ measured at $h v=800 \mathrm{eV}$. The sample temperature was $20 \mathrm{~K}$, and the sample was in the paramagnetic phase. (a) AIPES spectra measured in a wide energy range. (b) Ru $3 d$ core-level spectrum. (c) $U 4 f$ core-level spectrum.

\section{Results and discussion}

First, we show the AIPES spectra of $\mathrm{URu}_{2} \mathrm{Si}_{2}$ in the paramagnetic phases. Figure 1 summarizes the AIPES spectra of $\mathrm{URu}_{2} \mathrm{Si}_{2}$ measured at $h v=800 \mathrm{eV}$. The sample temperature was $20 \mathrm{~K}$, and the sample was in the paramagnetic phase. Figure 1 (a) shows the AIPES spectrum of $\mathrm{URu}_{2} \mathrm{Si}_{2}$ measured in a wide energy range. There are several peaks in the spectrum, and they are assigned to the core-level spectra of uranium, ruthenium, and silicon. The signal from valence band is much weaker than those from the core-levels, and it cannot be recognized clearly in this spectrum. Figure 1 (b) shows the $\mathrm{Ru} 3 d$ core-level spectrum of $\mathrm{URu}_{2} \mathrm{Si}_{2}$. The spectrum exhibits the spin-orbit splitting, and each peak has a relatively simple peak structure. Figure 1 (c) shows the $U 4 f$ core-level spectrum of $\mathrm{URu}_{2} \mathrm{Si}_{2}$. The spectrum exhibits a spin orbit splitting corresponding to $U 4 f_{7 / 2}$ and $\mathrm{U} 4 f_{5 / 2}$ components, but each of them has rather complicated structures. The main line has a long tail towards the higher binding energies, and the satellite structure is observed at about $7 \mathrm{eV}$ higher binding energies from the main line. This much complicated structure of the $\mathrm{U} 4 f$ core-level spectrum suggests that the $\mathrm{U} 5 f$ states in $\mathrm{URu}_{2} \mathrm{Si}_{2}$ are not in simple itinerant or localized states.

In Figure 2, we show the valence band and core-level spectra of $\mathrm{URu}_{2} \mathrm{Si}_{2}$ together with those of typical itinerant compound $\mathrm{UB}_{2}$ and localized compound $\mathrm{UPd}_{3}[13,14]$. Note that the number of $\mathrm{U} 5$ $f$ occupation number in $\mathrm{UPd}_{3}$ is 2 while it is nearly 3 in $\mathrm{UB}_{2}$.

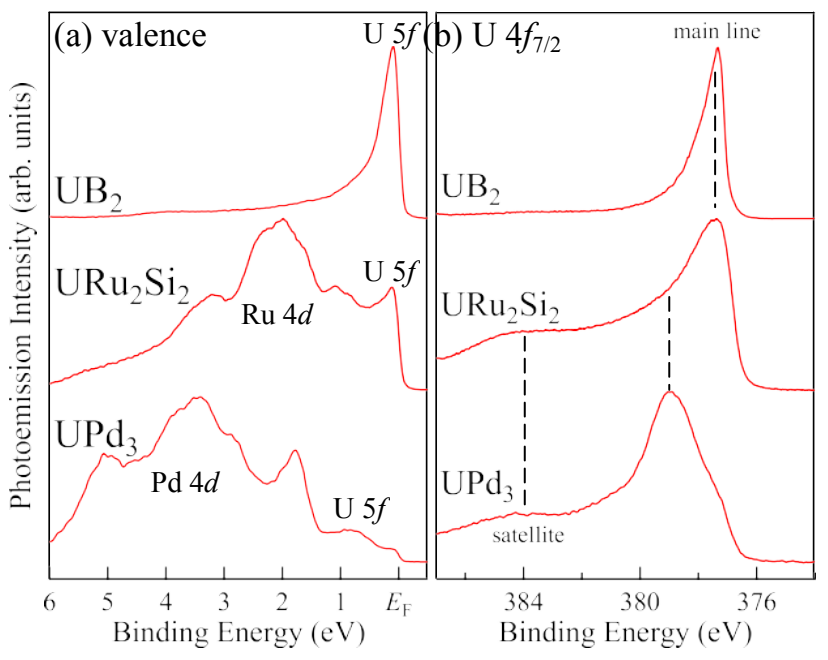

Figure 2. Valence band and core-level spectra of $\mathrm{URu}_{2} \mathrm{Si}_{2}$ together with typical itinerant and localized componds. (a) Valence band spectrum of $\mathrm{URu}_{2} \mathrm{Si}_{2}$ together with the itinerant compound $\mathrm{UB}_{2}$ and localized compound $\mathrm{UPd}_{3}$. (b) $\quad \mathrm{U}_{7 / 2}$ core-level spectrum of $\mathrm{URu}_{2} \mathrm{Si}_{2}$ together with the itinerant compound $\mathrm{UB}_{2}$ and localized compound $\mathrm{UPd}_{3}$.

Figure 2 (a) shows the comparison of their valence-band spectra. There is a sharp peak structure in the valence band spectrum of $\mathrm{UB}_{2}$, which is the contribution from the itinerant $\mathrm{U} 5 f$ state. The spectrum of $\mathrm{URu}_{2} \mathrm{Si}_{2}$ also has similar sharp peak structure at $E_{\mathrm{F}}$, suggesting that $\mathrm{U} 5 f$ states in $\mathrm{URu}_{2} \mathrm{Si}_{2}$ essentially have an itinerant character. On the other hand, there is no such peak structure in the valence-band spectrum of $\mathrm{UPd}_{3}$, and the $\mathrm{U} 5 f$ states are located at around $E_{\mathrm{B}} 0.8 \mathrm{eV}$. This is consistent with the localized $\mathrm{U} 5 f$ states in $\mathrm{UPd}_{3}$. Figure 2 (b) shows the comparison of their $\mathrm{U} 4 f$ core-level spectra. The $\mathrm{U} 4 f$ core-level spectra exhibit a wide variety of structures. The core-level spectrum of $\mathrm{UB}_{2}$ has a very simple peak structure, and its shape is very close to the core-level spectrum of simple metals, suggesting that the electron correlation effect is very weak in $\mathrm{UB}_{2}$. On the other hand, the core-level spectrum of $\mathrm{UPd}_{3}$ has much complicated structure. The main line of $\mathrm{UPd}_{3}$ is located on the higher binding energy side of $\mathrm{UB}_{2}$ by about $1.6 \mathrm{eV}$. Generally, the position of the core-level spectra is highly sensitive to the valence state. The main peak position of $\mathrm{URu}_{2} \mathrm{Si}_{2}$ is identical to that of $\mathrm{UB}_{2}$, suggesting that the valence state of uranium atoms in $\mathrm{URu}_{2} \mathrm{Si}_{2}$ is close to 3 as in the case of $\mathrm{UB}_{2}$. This is consistent with the result of recent $\mathrm{U}$ $L_{\text {III }}$ resonant X-ray emission spectroscopy study of $\mathrm{URu}_{2} \mathrm{Si}_{2}$ by Booth et al [15]. On the other hand, there exists the satellite structure in the core-level spectra of $\mathrm{URu}_{2} \mathrm{Si}_{2}$ and $\mathrm{UPd}_{3}$. This satellite structure has been observed in various metallic compounds [16] and oxides [17], and considered as the influence of electron correlation effects [18]. The finite satellite intensity in $\mathrm{URu}_{2} \mathrm{Si}_{2}$ suggests that there exist the electron correlation effect in $\mathrm{URu}_{2} \mathrm{Si}_{2}$. Therefore, the $\mathrm{U} 5 f$ state in $\mathrm{URu}_{2} \mathrm{Si}_{2}$ has essentially itinerant 

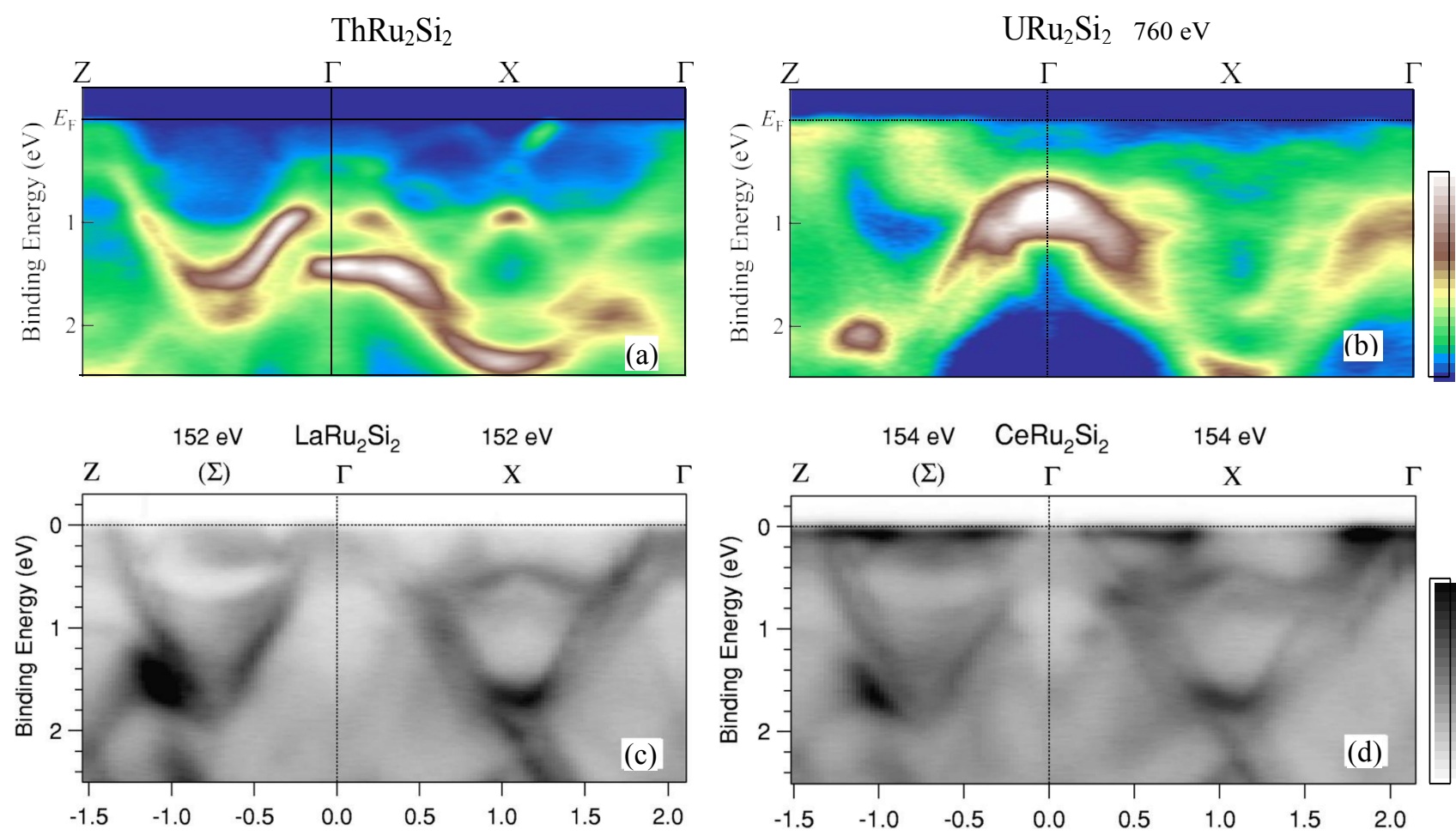

Figure 3. (Online color) Comparison of ARPES spectra of $\mathrm{ThRu}_{2} \mathrm{Si}_{2}, \mathrm{URu}_{2} \mathrm{Si}_{2}, \mathrm{LaRu}_{2} \mathrm{Si}_{2}, \mathrm{and}_{\mathrm{CeRu}} \mathrm{Si}_{2}$ in paramagnetic phase. (a) ARPES spectra of $\mathrm{ThRu}_{2} \mathrm{Si}_{2}$ measured at $h v=735 \mathrm{eV}$. (b) ARPES spectra of URu $\mathrm{Ui}_{2} \mathrm{Si}_{2} \mathrm{measured}$ at $h v=760 \mathrm{eV}$. (b) ARPES spectra of $\mathrm{LaRu}_{2} \mathrm{Si}_{2}$ measured at $h v=152 \mathrm{eV}$. (d) ARPES spectra of $\mathrm{CeRu}_{2} \mathrm{Si}_{2}$ measured at $h v=$ $154 \mathrm{eV}$.

The data of $\mathrm{LaRu}_{2} \mathrm{Si}_{2}$ and $\mathrm{CeRu}_{2} \mathrm{Si}_{2}$ were after [9]. Reprinted from Denlinger et al [9]. Copyright 2001, with permission from Elsevier.

character, but there also exists an electron correlation effect.

Figure 3 shows a comparison of ARPES spectra of $\mathrm{ThRu}_{2} \mathrm{Si}_{2}$ [8], $\mathrm{URu}_{2} \mathrm{Si}_{2}$ [7], $\mathrm{LaRu}_{2} \mathrm{Si}_{2}$, and $\mathrm{CeRu}_{2} \mathrm{Si}_{2}$ [9]. The photon energies used were $h v=735 \mathrm{eV}$ for $\mathrm{ThRu}_{2} \mathrm{Si}_{2}, 760 \mathrm{eV}$ for $\mathrm{URu}_{2} \mathrm{Si}_{2}, 152 \mathrm{eV}$ for $\mathrm{LaRu}_{2} \mathrm{Si}_{2}$, and $154 \mathrm{eV}$ for $\mathrm{CeRu}_{2} \mathrm{Si}_{2}$. The data of $\mathrm{LaRu}_{2} \mathrm{Si}_{2}$ and $\mathrm{CeRu}_{2} \mathrm{Si}_{2}$ were taken from Ref. [9]. The sample temperatures were $20 \mathrm{~K}$ for the cases of $\mathrm{ThRu}_{2} \mathrm{Si}_{2}$ and $\mathrm{URu}_{2} \mathrm{Si}_{2}$, and $<150 \mathrm{~K}$ for the cases of $\mathrm{LaRu}_{2} \mathrm{Si}_{2}$ and $\mathrm{CeRu}_{2} \mathrm{Si}_{2}$. Both sets of data correspond to the scan along the $\mathrm{Z}-\Gamma-\mathrm{X}-\Gamma$ high-symmetry line though the incident photon energies are considerably different between the cases of ( $\mathrm{U}, \mathrm{Th}) \mathrm{Ru}_{2} \mathrm{Si}_{2}$ and (Ce, $\mathrm{La}) \mathrm{Ru}_{2} \mathrm{Si}_{2}$. There are some similarities between the ARPES spectra of (U, Th) $\mathrm{Ru}_{2} \mathrm{Si}_{2}$ and (Ce, La) $\mathrm{Ru}_{2} \mathrm{Si}_{2}$. In particular, the parabolic dispersions with enhanced intensities and their apex at the $\Gamma$ point are very similar. On the other hand, their appearances are somewhat different due to the different matrix element effects in different photon energies. First, we focus on the comparison between the ARPES spectra of $\mathrm{ThRu}_{2} \mathrm{Si}_{2}$ and $\mathrm{URu}_{2} \mathrm{Si}_{2}$. They have essentially similar structures, but their details are considerably different. In particular, the features in the vicinity of $E_{\mathrm{F}}$ are very different between these two compounds. For example, there are dispersive bands in the vicinity of $E_{\mathrm{F}}$ along the $\mathrm{Z} \Gamma$ line in the ARPES spectra of $\mathrm{URu}_{2} \mathrm{Si}_{2}$, but there are no corresponding bands in the
ARPES spectra of $\mathrm{ThRu}_{2} \mathrm{Si}_{2}$. These dispersive features in the vicinity of $E_{\mathrm{F}}$ are contributions from $\mathrm{U}$ $5 f$ states, suggesting that $U 5 f$ have an itinerant nature in $\mathrm{URu}_{2} \mathrm{Si}_{2}$. On the other hand, the ARPES spectra of $\mathrm{LaRu}_{2} \mathrm{Si}_{2}$ and $\mathrm{CeRu}_{2} \mathrm{Si}_{2}$ are very similar each other, which is in contrast with the case of (U, $\mathrm{Th}) \mathrm{Ru}_{2} \mathrm{Si}_{2}$ The difference between the ARPES spectra of $\mathrm{CeRu}_{2} \mathrm{Si}_{2}$ and $\mathrm{LaRu}_{2} \mathrm{Si}_{2}$ is essentially limited only in the vicinity of $E_{\mathrm{F}}$, where the at peak was observed in some part of the Brillouin zone. They correspond to the contribution from itinerant component of $\mathrm{Ce} 4 f$ state, but their band dispersions are extremely narrow, suggesting that the Ce $4 f$ states are nearly localized in $\mathrm{CeRu}_{2} \mathrm{Si}_{2}$. An interesting point to note is that the $\mathrm{Ru}$ $4 d$ states are almost identical between the ARPES spectra of $\mathrm{LaRu}_{2} \mathrm{Si}_{2}$ and $\mathrm{CeRu}_{2} \mathrm{Si}_{2}$, while they are considerably different between the ARPES spectra of $\mathrm{ThRu}_{2} \mathrm{Si}_{2}$ and $\mathrm{URu}_{2} \mathrm{Si}_{2}$. This means that $\mathrm{U} 5 f$ states are considerably hybridized with the $\mathrm{Ru} 4 d$ states in $\mathrm{URu}_{2} \mathrm{Si}_{2}$ while Ce $4 f$ states are almost localized in $\mathrm{CeRu}_{2} \mathrm{Si}_{2}$.

\section{Conclusion}

We have studied the valence-band and core-level spectra of $\mathrm{URu}_{2} \mathrm{Si}_{2}$. The comparison of the core-level spectrum of $\mathrm{URu}_{2} \mathrm{Si}_{2}$ with those of $\mathrm{UB}_{2}$ and $\mathrm{UPd}_{3}$ suggests that the number of $\mathrm{U} 5 f$ occupation number 
in $\mathrm{URu}_{2} \mathrm{Si}_{2}$ is close to 3 as in the case of $\mathrm{UB}_{2}$. The comparison of ARPES spectra between (U, $\mathrm{Th}) \mathrm{Ru}_{2} \mathrm{Si}_{2}$ and (Ce, $\left.\mathrm{La}\right) \mathrm{Ru}_{2} \mathrm{Si}_{2}$ indicated that $\mathrm{U} 5 \mathrm{f}$ states are strongly hybridized with $\mathrm{Ru} 4 d$ states whereas Ce $4 f$ states in $\mathrm{CeRu}_{2} \mathrm{Si}_{2}$ are nearly localized in $\mathrm{CeRu}_{2} \mathrm{Si}_{2}$. According to these results, the $\mathrm{U} 5 \mathrm{f}$ states in $\mathrm{URu}_{2} \mathrm{Si}_{2}$ have strong itinerant character, but the finite contribution from the electron correlation effect exists.

\section{Acknowledgements}

The experiments were performed under Proposal Nos. 2015A3810, 2015B3810, 2016A3810 and 2016B3810 at SPring-8 BL23SU. The present work was financially supported by JSPS KAKENHI Grant Numbers 21740271, 26400374, 16H01084 (J-Physics), and 16K05463 from the Ministry of Education, Culture, Sports, Science, and Technology, Japan.

\section{References}

[1] C.Pfleiderer, Superconducting phases of $f$ electron compounds, Rev. Mod. Phys. 81 (2009), p. 1551.

[2] T.T. M. Palstra, A.A. Menovsky, J.v.d. Berg, A.J. Dirkmaat, P.H. Kes, G.J. Nieuwenhuys and J.A. Mydosh, Superconducting and magnetic transitions in the heavy-fermion system $\mathrm{URu}_{2} \mathrm{Si}_{2}$, Phys. Rev. Lett. 55 (1985), p. 2727.

[3] J.A. Mydosh and P.M. Oppeneer, Colloquium: Hidden order, superconductivity, and magnetism: The unsolved case of $\mathrm{URu}_{2} \mathrm{Si}_{2}$, Rev. Mod. Phys. 83 (2011), p. 1301.

[4] J. Mydosh and P. Oppeneer, Hidden order behaviour in $\mathrm{URu}_{2} \mathrm{Si}_{2}$ (a critical review of the status of hidden order in 2014), Philos. Mag. 94 (2014), p. 3642 .

[5] T. Durakiewicz, Photoemission investigations of $\mathrm{URu}_{2} \mathrm{Si}_{2}$, Philos. Mag. 94 (2014), p. 3723.

[6] S.-i. Fujimori, Band structures of $4 f$ and $5 f$ materials studied by angle-resolved photoelectron spectroscopy, J. Phys.: Condens. Matter 28 (2016), p. 153002.

[7] I. Kawasaki, S.-i. Fujimori, Y. Takeda, T. Okane, Yasui, Y. Saitoh, H. Yamagami, Y. Haga, E. Yamamoto and Y. Onuki. Band structure and fermi surface of $\mathrm{URu}_{2} \mathrm{Si}_{2}$ studied by soft x-ray angle-resolved photoemission spectroscopy, Phys. Rev. B 83 (2011), p. 235121.

[8] S.-i. Fujimori, M. Kobata, Y. Takeda, T. Okane, Y. Saitoh, A. Fujimori, H. Yamagami, M. Yuji, Y. Etsuji, N. Tateiwa and Y. Haga, Electronic structure of $\mathrm{ThRu}_{2} \mathrm{Si}_{2}$ studied by angle-resolved photoelectron spectroscopy: Elucidating the contribution of $\mathrm{U} 5 f$ states in $\mathrm{URu}_{2} \mathrm{Si}_{2}$. Phys. Rev. B 96 (2017), p. 125117.

[9] J. Denlinger, G.-H. Gweon, J. Allen, C. Olson, M. Maple, J. Sarrao, P. Armstrong, Z. Fisk and H.
Yamagami, Comparative study of the electronic structure of $\mathrm{XRu}_{2} \mathrm{Si}_{2}$ : probing the anderson lattice, J. Electron Spectrosc. Relat. Phenom. 117-118 (2001), p. 347.

[10] A. Yokoya, T. Sekiguchi, Y. Saitoh, T. Okane, T. Nakatani, T. Shimada, H. Kobayashi, M. Takao, Y. Teraoka, Y. Hayashi, S. Sasaki, Y. Miyahara, T. Harami and T.A. Sasaki, Soft $\mathrm{x}$-ray beamline specialized for actinides and radioactive materials equipped with a variably polarizing undulator, J. Synchrotron Rad. 5 (1998), p. 10.

[11] Y. Saitoh, Y. Fukuda, Y. Takeda, H. Yamagami, S. Takahashi, Y. Asano, T. Hara, K. Shirasawa, M. Takeuchi, T. Tanaka and H. Kitamura, Performance upgrade in the JAEA actinide science beamline BL23SU at SPring-8 with a new twin-helical undulator, J. Synchrotron Rad. 19 (2012), p. 388.

[12] S.-i. Fujimori, K. Terai, Y. Takeda, T. Okane, Y. Saitoh, Y. Muramatsu, A. Fujimori, H. Yamagami, Y. Tokiwa, S. Ikeda, T. Matsuda, Y. Haga, E. Yamamoto and Y. Onuki, Itinerant U $5 f$ band states in the layered compound $\mathrm{UFeGa}_{5}$ observed by soft $\mathrm{x}$-ray angle-resolved photoemission spec- troscopy. Phys. Rev. B 73 (2006), p. 125109.

[13] S.-i. Fujimori, T. Ohkochi, I. Kawasaki, A. Yasui, Y. Takeda, T. Okane, Y. Saitoh, A. Fujimori, H. Yamagami, Y. Haga, E. Yamamoto, Y. Tokiwa, S. Ikeda, T. Sugai, H. Ohkuni, N. Kimura and Y. Onuki. Electronic structure of heavy fermion uranium compounds studied by core-level photoelectron spectroscopy, J. Phys. Soc. Jpn. 81 (2012), p. 014703.

[14] S.-i. Fujimori, Y. Takeda, T. Okane, Y. Saitoh, Fujimori, H. Yamagami, Y. Haga, E. Yamamoto and Y. Onuki, Electronic structures of uranium compounds studied by soft x-ray photoelectron spectroscopy, J. Phys. Soc. Jpn. 85 (2016), p. 062001.

[15] C.H. Booth, S.A. Medling, J.G. Tobin, R.E. Baumbach, E.D. Bauer, D. Sokaras, D. Nordlund and T.-C. Weng, Probing $5 f$-state con gurations in $\mathrm{URu}_{2} \mathrm{Si}_{2}$ with $\mathrm{u} L_{\mathrm{III}}$-edge resonant x-ray emission spectroscopy, Phys. Rev. B 94 (2016), p. 045121.

[16] J. Allen, J.-S. Kang, Y. Lassailly, M. Maple, M. Torikachvili, W. Ellis, B. Pate and I. Lindau, Electron spectroscopy study of the heavy fermion compound $\mathrm{URu}_{2} \mathrm{Si}_{2}$, Solid State Commun. 61 (1987), p. 183.

[17] Y. Baer and J. Schoenes, Electronic structure and coulomb correlation energy in $\mathrm{UO}_{2}$ single crystal, Solid State Commun. 33 (1980), p. 885.

[18] W.-D. Schneider and C. Laubschat, $5 f$-electron localization in uranium compounds, Phys. Rev. Lett. 46 (1981), p. 1023. 